\title{
ANY SPACE LEFT? HOMELESS RESISTANCE BY PLACE-TYPE IN LOS ANGELES COUNTY ${ }^{1}$
}

\author{
Geoffrey DeVerteuil ${ }^{2}$ \\ School of Geography \\ University of Southampton \\ Southampton, United Kingdom
}

Matthew Marr

Department of Sociology and Anthropology

Florida International University

\author{
David Snow \\ Department of Sociology \\ University of California, Irvine
}

\begin{abstract}
This study develops a more nuanced concept of homeless resistance, incorporating a range of resistance behaviors (exit, adaptation, persistence, and voice) that bridge the gap between current frameworks that either romanticize or ignore it. We also consider the possibility that different kinds of space may theoretically allow for different kinds of resistance. To this end, we employ an ecological approach to homeless space by classifying Los Angeles County into three place-types (prime, transitional, and marginal). We empirically consider the issue of resistance within the hardening context among a group of 25 homeless informants, focusing on whether and how some of them have exercised their voices and sought to ameliorate one or more aspects of their situation, as well as how resistance may vary by place-type. [Key words: homelessness, resistance, urban ecology, Los Angeles.]
\end{abstract}

During the late 1990s, the issue of homelessness seemingly disappeared from geographical research, a victim of the booming economy and academic fatigue (DeVerteuil and Wolch, 2002). Since the early 2000s, however, interest in homeless people has surged, largely as a result of hardening measures to expel them from highly used and valued public spaces. At the behest of the local state and businesses worried about image, public safety, and livability, anti-homeless ordinances have been systematically implemented to outlaw certain behaviors and survival techniques in public spaces, including aggressive panhandling, camping, sleeping, sitting, loitering, urinating, and, in some cases, even providing free meals to the hungry (Mitchell, 1997; Merrifield, 2000; Collins

\footnotetext{
${ }^{1}$ We wish to acknowledge the support of a grant from the National Science Foundation (SES-0213372, David Snow, Principal Investigator). We would like to thank the National Science Foundation and all of the individuals who responded to interviews used in this article.

${ }^{2}$ Correspondence concerning this article should be addressed to Geoffrey DeVerteuil, School of Geography, University of Southampton, Southampton, Hants SO17 1BJ, United Kingdom; telephone: +44 (0)23 8059 9622; fax: +44 (0)23 8059 3295; email: g.p.deverteuil@soton.ac.uk
} 
and Blomley, 2003; National Coalition for the Homeless, 2007). Although the actual impacts of these constraints on the everyday lives (and geographies) of homeless people have perhaps been overstated (DeVerteuil et al., 2009), this hardening context does hold critical implications for the rights of homeless people, particularly their ability to access and occupy public space.

Going further, we know relatively little about the extent to which homeless individuals (or collectives) are actually practicing resistance within the context of escalating antihomeless measures. Resistance is the most obvious way in which homeless people can demand certain basic human rights, such as freedom of movement (or staying put) and freedom of speech. Second and critically, our current understanding of homeless resistance remains stymied by a dichotomy between the romance of resistance versus ignoring resistance altogether. Not only are these perspectives diametrically opposed, they also come with their own specific role for space, either enabling resistance or crushing it, respectively.

In this study, we address both of these gaps. We reconceptualize homeless resistance, incorporating a more nuanced range between the two polarized extremes, along with the possibility that different kinds of space may theoretically allow for different kinds of resistance. For both, we use Snow and Mulcahy's (2001) approach to homeless resistance, which positions it along a continuum from exit and adaptation to persistence and voice, as well as their ecological approach to homeless space that divides Los Angeles County into three place-types (prime, transitional, and marginal), thereby allowing resistance to potentially vary by place-type. We empirically consider the issue of resistance among a group of 25 homeless informants, focusing on whether and how some of our informants have exercised their voices and sought to ameliorate one or more aspects of their situation, and also on how resistance may vary by place-type.

\section{RECONCEPTUALIZING HOMELESS RESISTANCE}

From the outset, our understanding of the currently hardening attitude toward homeless people is marked by a certain ambivalence. Whereas we fully acknowledge the rising popularity and escalating meanness of anti-homeless laws, as well as their critical implications for the rights of homeless people to access and occupy public space (Laurenson and Collins, 2007; National Coalition for the Homeless, 2007), we also recognize that more accommodative responses work alongside the increasingly punitive measures, allowing for varied and complex spaces of homelessness that belie any sense of "collapsing" homeless geographies (DeVerteuil, 2006; DeVerteuil et al., 2009). In effect, we have witnessed a concurrent squeezing of homeless people from certain prime public spaces coinciding with a dramatic expansion in other homeless spaces, such as shelters, refuges, prisons, drop-in centers, and rooming houses. As DeVerteuil et al. (2009) contend, it is to these spaces that homeless people are migrating, thus engendering a disarticulated expansion of the spaces of homelessness across the city.

This ambivalent position provides a more nuanced starting point for understanding and reconceptualizing homeless resistance, given that current conceptualizations of homeless resistance remain outdated, polarized, and geographically narrow. Reconceptualizing resistance is also essential in unpacking and rejecting the persistently negative representations of homeless people as stigmatized, powerless, and disaffiliated 
(Takahashi, 1996). Before reconceptualizating homeless resistance, it is useful to revisit everyday individual agency. Although various structural constraints may impede everyday survival, homeless people may also exercise considerable discretion. This "constrained agency" balances the notion of homeless people as "rational decision makers who can and do negotiate their social worlds" (Molina, 2000, p. 669) with fundamental structural constraints (e.g., extreme poverty, excessive unemployment, lack of affordable housing, and recently escalating anti-homeless policies) that set boundaries for all behavioral choices. Moreover, we do not wish to conceal the sometimes negative aspects of homeless agency, but rather place these acts within the larger drive for survival. Many adaptive survival patterns that help in the short term may actually make it more difficult to escape homelessness in the long term (Wolch and Dear, 1993).

Set within this constrained agency, homeless people are able to engage in what can be termed resistance. The definition of resistance very much depends on the approach taken. As a starting point, we draw upon the position set out by Sharp et al. (2000), who conceived resistance as a form of power that is necessarily entangled with, and cannot be uncoupled from, domination. In this way, we move beyond conceiving power as always domineering. More specifically, resistance involves "that power which attempts to set up situations, groupings and actions which resist the impositions of dominating power" (Sharp et al., 2000, p. 3).

Accounts of homeless resistance (and the role of space in them) have been polarized between being romanticized and being largely ignored, with little room in between. When homeless resistance was acknowledged at all, it was typically romanticized, part of a trend in the 1990s aimed at "detecting in all kinds of activities the expression of a resistant spirit refusing to knuckle under the yoke of domination" (Sharp et al., 2000, p. 11). To Ruddick (1996), homeless people resist by their very existence and ability to "talk back," their rejection of the marginal spaces "chosen" for them by institutions, and their use of tenuous and transient "tactics of place" to negotiate - if not contest - their marginality and assigned identities. Wagner (1993, p. 3) used instances of homeless opposition to dominant norms, as well as sporadic collective action, to challenge the "dominant portrayal of homeless people as vulnerable and dependent people worthy perhaps of sympathy but judged to be socially disorganized, disaffiliated, and disempowered" than to truly demonstrate significant societal fault lines. To Hopper (2006), the ability to salvage some measure of self-respect by refusing services or shelter constituted a last-resort form of resistance to the infantilizing tendencies of the welfare state. Throughout this literature, space always has the potential to be liberating and open to challengingperhaps even reversing - the stigmatized identities of homeless people (see also Wright, 1997; Molina, 2000).

The shortcoming of this approach is that it incorrectly equated adaptive and transgressive behavior (e.g., concealing presences) with consequential ruptures of society. Although useful in counterbalancing the view of homeless people as powerless, this approach seemed to find resistance in every mundane and ephemeral tactic of everyday survival - the so-called "weapons of the weak" (Abu-Lughod, 1990; Brown, 1996). As Cresswell (1996, p. 175) effectively contended, the intention of transgression cannot be to radically overthrow or transform the social order, but rather to destabilize and critique it through inappropriateness: "transgression's efficacy lies in the power of the established 
boundaries and spaces that it so heretically subverts. It is also limited by this established geography; it is always in reaction to topographies of power."

For the most part, however, everyday homeless resistance has largely been ignored, particularly since the dominant perspective on homelessness since the 1990s has become a singularly punitive framework that downplays, if not wholly ignores, homeless agency (e.g., Smith, 1996; Mitchell, 1997). Whereas it is enormously influential in framing the geographies of homelessness, as well as bringing much-needed attention to worrisome trends surrounding public space in U.S. cities, this literature offers few insights into how homeless people react to - or perhaps even resist - the steamroller of anti-homeless laws designed to banish them from the streets (DeVerteuil et al., 2009; see also Wyly and Hammel, 2005, on the need for a more empirical approach within the punitive framework). The voices of homeless people themselves are rarely heard in the (largely secondhand) punitive accounts, appearing outmatched in the face of overwhelming pressures to displace and evict. When homeless resistance is considered at all, it tends to be in the form of riots (e.g., Smith's account of Thompkins Square in New York City in 1988; Smith, 1996) that are as rare as they are spectacular (DeVerteuil et al., 2009). However, everyday homeless resistance behavior and the struggle for the "right to place/housing" are not considered (Hartman et al., 1982; Bratt et al., 2006). So by default, space within the punitive framework tends to obscure homeless people, crushing and denying their presence.

Our aim is not to dismiss these approaches, but rather to extend them in a more nuanced fashion. Even though the punitive framework tends to reduce homeless people to ciphers of troublesome political/economic/legal trends shaping public space in urban America, the "romantic resistance" literature at least insists that homeless people do exercise some agency and tenacity in coping with their everyday situations, voiced firsthand by homeless people themselves. This insistence is based on careful ethnographic research that details individual voices and struggles. As Culhane and Fried (1988, p. 185) noted, a key task for researchers is to "provide a place for homeless people to contest the naming and stigmatization which silences them and to challenge the formulation of homelessness which relegate them to an undignified, dehumanized space." Ethnographic work done by May (2000a, 2000b) extends this careful analysis of homeless behavior, in which the language and struggles of homeless people are brought to the fore of the analysis, rather than as background to broader trends and narratives. A more recent example of this kind of work is Johnsen et al. (2008, p. 194), who actually allowed homeless people to use autophotography to enable a re-examination of homeless geographies, illuminating " "hidden spaces' spaces that do not typically feature in public (or academic) imaginations of homelessness, and providing more nuanced understandings of the use, meanings and dynamics associated with other, apparently already 'known' spaces."

In response, we employ a more wide-ranging approach to homeless resistance that positions it along a continuum from exit and adaptation to persistence and voice. This builds on Snow and Mulcahy's (2001) elaboration of this typological continuum, itself a refinement of Hirschman's (1970) classic distinction between exit, voice, and loyalty. Exit occurs when homeless people leave the contested situation or space, and more readily constitutes evasion than active resistance. Adaptation entails the modification of one's behavior in situ, rather than moving to another place. An example would be individuals trying not to "look homeless" while staying put. Persistence occurs when a homeless 
person neither leaves nor modifies his/her behavior. Finally, voice entails explicit and collective dissatisfaction with the treatment of homeless people, and includes collective and organized social protest (see also Culhane and Fried, 1988). Voice, therefore, differs from the more individualized responses of exit, adaptation, and persistence.

Along with this more wide-ranging reading of resistance, we also want to integrate a more methodologically sophisticated and geographically expansive concept for the role of space within homeless resistance. Almost all studies of homeless resistance are narrowly small-scale, qualitative, geographically selective, and intensive, and as such do not embed resistance behavior within the broader socioeconomic spaces of the metropolitan area, nor do they extend to include a "big picture" quantitative assessment of the placeresistance relationship. This builds on the methodologically provocative work by Wyly and Hammel (2005) on punitive (homeless) policies across multiple metropolitan areas. We acknowledge the necessarily microgeographical nature of homeless resistance, but we also contend that part of the innovation of this article is that we embed the well-studied microgeographies of homeless resistance within, and relating to, the macro scale. Previous studies narrowly relied on resource-rich, inner-city areas, telling us little about how resistance behavior occurs (or not) in more suburban and exurban, ethnic, transitional, or even wealthy, exclusive areas. Returning to Sharp et al. (2000, p. 27), we acknowledge their conception of an inherently geographic entanglement of domination and resistance, in which space "constitutes the active medium through which the relations of domination/ resistance can be discerned and assessed." This suggests the possibility that different kinds of space may theoretically allow for different kinds of resistance, beyond the polarized role of space in enabling or denying resistance.

One way to operationalize such a differentiated and expansive approach is to adopt Snow and Mulcahy's (2001) categorization of urban space into three place-types: prime, marginal, and transitional. Prime spaces are used by upper-income populations for everyday commercial and symbolic purposes. Alternatively, marginal space has less value for these groups but holds more value for low-income populations. Transitional space coalesces elements of both prime and marginal uses and/or to act as a cushion between them. Marginal space is essential to homeless people, because it contains the bulk of their sustaining resources. These include places to sleep on the street with minimal police intrusion as well as shelters, cheap hotels, and affordable (albeit lowest-rung) housing, and the like. How marginal space is accessed and distributed is crucial in shaping of the geography of homeless survival patterns. However, the proximity of prime space is also important, as it provides opportunities for scavenging, recycling, and especially panhandling that may not exist in marginal spaces.

Theoretically, each of these spaces has potentially different likelihoods for our reconceptualized homeless resistance behavior (Table 1). We can suggest that exit would be most likely in prime spaces, given the greater degree to which homeless people are "out of their element" in such places, as well as the general lack of a dense array of supportive services. Adaptation strategies, such as trying not to look homeless, would be likely in prime spaces, somewhat likely in transitional spaces, and rather unlikely in marginal spaces. For persistence, it would be unlikely in prime spaces (people would be simply "pushed" along), somewhat likely in transitional spaces (less pressure to "move along"), and quite likely in marginal spaces. Given that social service organizations provide a vehicle for its spatial dispersal, voice would be very unlikely in prime spaces, unlikely in 
Table 1. Theoretical Resistance Behavior Across the Three Place-Types

\begin{tabular}{llll}
\hline $\begin{array}{l}\text { Place-type and } \\
\text { resistance behavior }\end{array}$ & Prime space & Transitional space & Marginal space \\
\hline Exit & Very likely & Likely & Unlikely \\
Adaptation & Likely & Somewhat likely & Somewhat unlikely \\
Persistence & Unlikely & Somewhat likely & Very likely \\
Voice & Very unlikely & Unlikely & Likely \\
\hline
\end{tabular}

transitional, but likely in marginal spaces. Marginal spaces, theoretically, would be the most radical and open, with prime spaces being the least. These hypothesized outcomes will be further calibrated when we apply them to the Los Angeles context.

\section{METHODOLOGY}

Let us apply this reconceptualized, geographically variegated approach to homeless resistance in an empirical setting, and begin by employing the tripartite division of urban space (prime, marginal, and transitional) just discussed. Using Los Angeles County as our case study, we will first map the three types of space utilizing several strategic socioeconomic variables at the census tract level. Given that we were seeking to identify three predesignated spaces, we used a k-means cluster analysis designed to identify these (cluster) spaces. This statistical procedure is regularly employed in geodemographic analysis to reduce large quantities of data, seeking to identify relatively homogeneous groups of observations based on selected variables. As a nonhierarchical and unsupervised technique, k-means cluster analysis requires an a priori specification of the number of clusters (Rogerson, 2001); for the purposes of this study, it will be the three pre-designated spaces (marginal, transitional, and prime). The use of this technique maximizes intragroup cohesion and intergroup variability, allows for replicability, and represents an efficient tool to quickly classify, partition, and reduce the massive amount of socioeconomic data associated with complex and multifaceted urban regions.

Ten socioeconomic variables from the 2000 Census were identified for their effectiveness in differentiating place-types within Los Angeles County, acting essentially as proxies for marginal, prime, and transitional spaces. We selected census variables that would cover race, poverty, citizenship and language, and housing status, all influenced by Sassen's global city polarization thesis (2001) that posits large gaps between welleducated élites and recent immigrant, low-wage populations. The specific variables were: ${ }^{3}$ Race — $\%$ White non-Hispanic (one race response); Income- $\%$ of households on public assistance (general assistance - in this case, GR; and Temporary Aid to Needy Families, but not in-kind assistance or Supplemental Security Income) and \% of population

\footnotetext{
${ }^{3}$ See also Rogerson (2001) regarding the use of the these variables.
} 
under the poverty line; Citizenship/language_ $\%$ of households linguistically isolated (i.e., a household in which all members 14 years or older speak a non-English language and also speak English less than "very well"), \% of total population who are recent immigrants (i.e., year of entry between 1990 and March 2000), and \% of total population who are American citizens; Housing — $\%$ of occupied units that are owned, $\%$ of occupied units with two or more occupants per room (to measure overcrowding), and \% of occupied units that are single, detached units; and Education- $\%$ of population over 25 with a university degree. Each of the percentage variables were then standardized into Zscores (Rogerson, 2001). Once identified, we profiled these spaces according to their immediate ability to sustain homeless survival, focusing on the location of emergency shelter beds using the 2000 Shelter Partnership database (Shelter Partnership, 2000). Although not all homeless people rely on shelters, they certainly constitute a critical node for survival for most over time (Hopper et al., 1985).

These variables were useful in discriminating between prime spaces, occupied by largely White, upper-income, well-educated, native-born inhabitants, and marginal spaces, occupied by largely non-White, immigrant, low-education, lower-income inhabitants - the major division said to characterize polarized global city-regions such as Los Angeles (Scott, 2001). Transitional areas are those "in-between," comprised primarily of lower-middle class inhabitants. Because our analysis is dependent on residential data at the census tract level, it was not possible to account for the daily shifts in prime/marginal/ transitional space. For instance, daytime Downtown Los Angeles may be considered prime-especially given extensive residential upgrading and a plethora of mega-projects (Wolch, 2008) - but marginal at night; however, our analysis classifies almost all of its tracts as marginal.

With the cluster analysis providing a countywide mapping of different potential spaces for homeless resistance, the next step is to empirically examine whether these spaces are actually embedded with different resistance behaviors. Here we rely on 25 in-depth, life history interviews with homeless informants dispersed across these spaces in Los Angeles County. The interviews were designed to elicit systematic biographic commentary from homeless informants, including resistance behaviors. Our sampling strategy was guided by the three place-types, and leaned toward a purposive rather than a random or probability-based approach. Purposive sampling is appropriate when population parameters are difficult to perceive, as in the case of an urban homeless population. Because one of our interests was to discern variability among homeless resistance behaviors across different place-types, we employed a purposive field sampling strategy deemed maximum variation sampling. The latter aims to identify the diversity or range of the phenomena of interest (Erlandson et al., 1993; Lofland, 2006). Accordingly, we can identify the various niches or contexts in which homeless people might practice resistance behavior and then try to include individuals associated with those niches in the field sample. Overall, 13 homeless people were living in marginal space, 7 in transitional space, and 5 in prime space. Most of our respondents were contacted via introductions from the staffs of various private nonprofit organizations that provided assistance to persons living on the streets or in shelters. The typical informant was male, in his $40 \mathrm{~s}$, a person of color, and on welfare. 
Table 2. Selected Sociodemographic Characteristics by Place-Type ${ }^{\mathrm{a}}$ (IN PERCENT)

\begin{tabular}{lccc}
\hline \hline & Cluster & Cluster & Cluster \\
Selected sociodemographic & $\begin{array}{c}\text { 1 } \\
\text { and economic characteristics }\end{array}$ & $\begin{array}{c}2 \\
\text { marginal }\end{array}$ & prime \\
\hline White non-Hispanic & 7.4 & 20.3 & 60.7 \\
Households on public assistance & 13.8 & 7.2 & 2.2 \\
Residents in poverty & 33.7 & 18.0 & 6.6 \\
Residents linguistically isolated & 34.5 & 15.0 & 5.6 \\
Recent immigrants & 22.2 & 11.9 & 5.8 \\
U.S. citizens & 60.4 & 76.4 & 90.0 \\
Owner-occupied housing & 21.0 & 45.1 & 67.2 \\
2 or more persons per room & 21.5 & 8.1 & 1.0 \\
Single detached housing & 31.0 & 56.0 & 72.6 \\
University degree & 11.1 & 22.8 & 47.6 \\
\hline
\end{tabular}

${ }^{\mathrm{a} S o u r c e: ~ U . S . ~ C e n s u s ~(2000) . ~}$

\section{THE LOS ANGELES COUNTY CONTEXT}

In this section, we: (1) report the results of the cluster analysis; (2) describe the kinds of constraints and pressures on homeless people that exist in prime, transitional, and marginal spaces, and (3) calibrate our expectations about what kinds of resistance behavior may occur in these actual place-types. Table 2 outlines the three general place-types in Los Angeles County.

Goodness of fit was measured by an ANOVA F-Statistic (Levia and Page, 2000; Rogerson, 2001). It was found that all of the variables had high and significant F-values (between 444 and 2,198), thus roughly indicating the success of the technique in differentiating the three clusters, as well as the success of each variable in contributing to the overall differentiation. These spatial clusters may be perceived as a socioeconomic gradient, moving from largely non-White, poor, heavily immigrant, overcrowded, renter, and undereducated areas (Cluster 1) to largely White, middle/upper class, U.S.-born, owner, and well-educated areas (Cluster 3). Cluster 2 most closely approaches dounty median values. Table 2 confirms the deep socioeconomic polarization within Los Angeles County, highlighted geographically when the clusters are mapped by census tract $(n=$ 2,054), as shown in Figure 1.

Based on the data shown in Table 2 and Figure 1, an overall profile of each place-type cluster can be developed. Beginning at the center of a roughly concentric pattern, Cluster 1 represents marginal spaces. This cluster includes the largely immigrant, impoverished, and contiguous core of Los Angeles County (Downtown, East Los Angeles, Koreatown, Hub Cities) as well as suburban and even exurban nodes (such as Long Beach, Glendale, the San Fernando Valley, Pomona, and Palmdale/Lancaster). Cluster 2 (transitional 


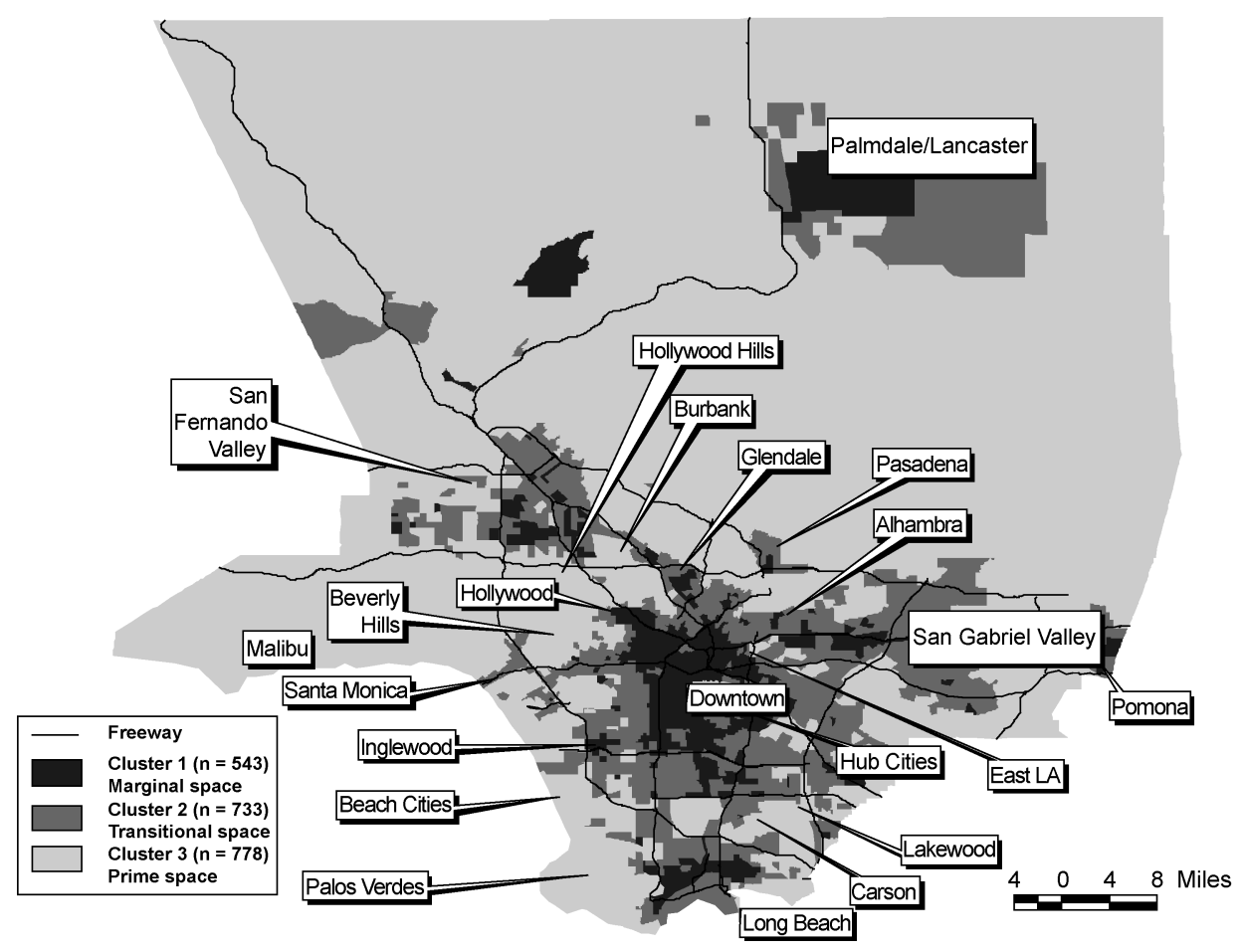

Fig. 1. Prime, transitional, and marginal spaces in Los Angeles County by census tract.

spaces) roughly represents the next ring in the concentric pattern, generally innersuburban areas with mixed-income and less heavily immigrant populations. These areas are especially common to the east (e.g., San Gabriel Valley) and south (e.g., Carson and Inglewood) of the central core; they also tend to be lower in density, ethnically mixed, and at risk of downgrading or upgrading. Cluster 3 occupies the outermost ring (prime spaces), including foothill and beach communities (e.g., Malibu, Santa Monica, Palos Verdes, Hollywood Hills, and Beverly Hills), as well as certain inner areas that have maintained their socioeconomic integrity (e.g., Burbank and Lakewood). Heavily middle/ upper class and White, these areas are exclusive and affluent.

Each place-type differs by levels of tangible support for homeless people in the form of emergency shelter beds. In April 2000, Los Angeles County had 12,222 beds that could be mapped, with the remaining 800 or so beds part of shelters (especially battered women) without a street address (Shelter Partnership, 2000). As Table 3 demonstrates, beds are concentrated in marginal spaces, with progressively fewer as one moves to transitional and prime spaces. When measured in per capita terms as shelter beds per very poor persons (below $50 \%$ of the poverty line), we find that emergency shelter beds are even more disproportionately clustered in marginal spaces.

Given that resistance is always intertwined with power, it is important to map some of the strategies of those in power over homeless people in these different place-types. Prime spaces in Los Angeles County have persistently been hostile toward and exclusionary of 
TABle 3. Share of Total County EMERgency Shelter Beds By Cluster, 2000

\begin{tabular}{lccc}
\hline \hline & & Emergency shelter beds \\
Total number of beds & $\begin{array}{c}\text { Percentage of total } \\
\text { county beds }\end{array}$ & $\begin{array}{c}\text { persons (below 50\% of the } \\
\text { poverty line) }\end{array}$ \\
\hline Cluster 1 & 6,908 & $57 \%$ & 198 \\
Cluster 2 & 4,120 & $34 \%$ & 145 \\
Cluster 3 & 1,194 & $9 \%$ & 100 \\
Total & 12,222 & & \\
\hline
\end{tabular}

${ }^{\mathrm{b}}$ Source: Shelter Partnership (2000).

homeless people, their services and poor people in general. This usually takes the form of NIMBY sentiments that prohibit homeless services and involve more stringent policing of public space (Wolch and Dear, 1993). More recently, however, a similar hostility has emerged within marginal, and to a lesser extent, transitional spaces. Since the late 1990s, marginal spaces such as Hollywood, Koreatown, Downtown Long Beach, and Downtown Los Angeles have been revitalizing, accompanied by growing anti-homeless activity such as indiscriminate sweeps and greater enforcement of anti-panhandling laws (Wolch, 2008). As a result, homeless people are at greater risk of being displaced. Our interviews took place in 2003, just when this added pressure was becoming apparent at street level. Calibrating our expectations from Table 1, we would anticipate increased pressure on marginal (and even transitional) spaces, such that overt resistance might prove less likely.

\section{HOMELESS RESISTANCE: EXIT, ADAPTATION, PERSISTENCE, AND VOICE}

In this section, we address our initial concern about the extent of the four types of resistance behavior, and then how these types of resistance behavior vary by place-type. Given that only 25 homeless informants were interviewed, we cannot make claims about a strong relationship between marginal, transitional, and prime spaces and the typical homeless resistance behaviors therein. Rather, the case study explores the relationship between the microgeographical spaces of homeless resistance and the broader placetypes already identified in the cluster analysis. A final caveat: the names of homeless informants used below are pseudonyms.

\section{Exit}

The incredible amount of energy required just to survive, particularly in prime spaces with relatively few homeless services or housing, was a strong impediment to voice resistance. The vast majority of the informants $(n=20)$ recounted instances in which they complied when asked to "move along," and almost all felt that things had "gotten worse" for homeless people in terms of being watched, harassed, and displaced. Winston, a 
39-year-old White man who experienced episodic homelessness for more than 10 years, could not help but see changes for the worse since the early 1990s:

The first time I had ended up homeless to this time, I've noticed a drastic change and not for the better. A lot of people have the tendency to paint all of us as drug users and alcoholics, but we're not all that way but that is how they paint us. I myself am a drug addict but I openly admit to that ... when I ended up in the streets the first time, it seemed like there was more of a caring attitude towards homeless people. That could be just because of how I perceived it, but it seems [now] like everyone wants to get rid of homeless people. I don't know where they expect to put 'em, but even having this facility here, the neighbors here, they don't want this here. If they could find a way to shut this place down, they would, believe me.

This harshness was as pervasive in the spaces of more transitional and marginal suburban and even exurban parts of Los Angeles County as it was in prime urban areas. In Downtown Long Beach, Darren (a 33-year-old African American) pointed out that finding a place to hang out is

an impossibility ... Downtown Long Beach Business Association and the Police Department have a set organized plan to harass homeless people wherever we are at and they do a very good job at it. With my warrants, I have to kind of toe the line, not congregate nowhere, I can't hang out in the park anymore because they might do a sweep through there.

In Downtown Pomona, a transitional area, Scott (a 27-year-old White male) noticed how the treatment of homeless people had worsened over time:

They've always been strict but ... lately it's been more since the [Cold Weather] shelter closed [for the summer]. Right now, on the corner of Mission and Gary they're making a complex, it's gonna be businesses and condos on top.... It's right across from the library and they don't want homeless people hanging around there ... so the city can say that they ain't got no homeless problem.

As Ricardo, a 37-year-old Latino male living in his car in far-flung Lancaster put it, "it's been hectic [to find a place to sleep outside]... It's like I'm running out of places." The police ask him to move his car, a late 1980s Honda Civic he bought for around \$200, and so Ricardo spends his nighttime hours driving around and living in a park during the day. When asked about how homeless people are treated in general, he says

real shitty. Some people don't want to get off their ass and do something about it but there are some people out here who do, you know? But if they, you know, if America would just give us a chance, because we're all not that bad.

Ricardo's enhanced mobility allows him to transcend the place-boundedness of so many homeless people, although he is still constrained by police harassment when driving his car.

Conversely, we should note that some homeless informants actively used exit as a material or psychological survival technique, rather than merely being asked to move 
along (see also DeVerteuil, 2003). For instance, several informants routinely left the marginal spaces of the Downtown L.A. Skid Row for a mental or physical respite, including treks to the more salubrious prime spaces of Santa Monica. Doc, a 65-year-old White male of French Canadian decent, frequently moved long distances around the San Fernando Valley. This is a large area that combines prime, transitional, and marginal spaces, in which he alternates between motels, shelters, and the streets. He tended to behave more discreetely when moving through obviously prime spaces, but less so in marginal areas where he actively recycles.

\section{Adaptation}

Adaptation entails the modification of one's behavior in situ, rather than moving to another place. An example would be individuals trying not to "look homeless" while staying put. The vast majority of homeless informants engaged in adaptation and subterfuge to stay in place, mostly in the form of not appearing homeless so as to avoid police harassment and public humiliation. Darren in Long Beach recounted his ability to not appear homeless:

I don't think that most people who encounter me know that I am homeless. I change clothes regularly, I bathe regularly, I shave regularly... You know, they don't know that I'm homeless when I walk into a restaurant. What do they care that I'm homeless or not, when I'm paying for my meal? Who cares? I don't wear dirty clothes, you know, I respect myself and I respect them.... It's all about really how you carry yourself. I'm one person they [police] don't really bother. I could be sitting in the park and they'll do a sweep and if I'm reading a book or eating a sandwich, they more than likely to just ride past me.

When asked about carrying her possessions around, Dawn, a 41-year-old White woman living in a winter shelter near prime spaces, took great pains to distinguish herself from the "cart pushers":

No, well I get looked at no matter what, but the only thing when they're pushing shopping carts and stuff, then you get, "Damn!" That right there is a mark and I won't go there. I will carry a bag or whatever, but even knowing the fact that I know that I am but they don't know it. But, lately a lot of people carry their backpacks and you can’t just classify everybody as homeless.

Similarly, Doc, who despite being literally homeless in the San Fernando Valley and living off panhandling, strived for a clean appearance:

People ask me "how come you're dressed so nicely? You don't look like you're homeless?" I thought, "what, you gotta be dirty and stink that way?" Some people are that way and other people aren't. I make myself look like I'm clean.

Winston noted that 
if you look clean, they don't bother you ... when I was pushing my little shopping cart and cops would stop me and now I can be with other people and be clean and shaven and they don't even ... I notice the difference, it's like night and day.

Of course, we should mention that only some homeless informants had the wherewithal and resources to pass as nonhomeless. Those with mental illnesses, severe substance abuse, or extremely irregular survival patterns that rarely involve homed episodes or access to hygiene may find it impossible to erase the visual stigma of being homeless. For those who cannot help but "look homeless," unwanted harassment from the police was more prevalent (see also von Mahs, 2005, on the distinctions between appearing and not appearing to be homeless).

Finally, in a park in East Los Angeles (marginal space), Ronaldo (a 46-year-old Mexican-American) made sure he "keeps the area clean" so not to give an excuse to be expelled. As he explained,

the guys in the park, they know me. I grew up with them. They tell me, "Hey man, I'll bring you a broom." I say, "Give me a broom and a pan." I pick up all the trash.... I even help them put it in the truck. They help me out. I mean, you know, not like money wise but they help me out with like plastic bags, they give me a plastic bag to cover my blankets.

Adaptation has always been a key feature of homeless survival, and it seems increasingly the first option when resisting an increasingly constrained set of marginal and transitional spaces. Moreover, as previously mentioned in the case of Doc, the majority of homeless informants calibrated their adaptive behavior to the setting-more discreet behavior and appearance in prime spaces, less so in marginal spaces where recycling in particular is a common practice even among the housed population.

\section{Persistence}

Persistence occurs when homeless people neither leave nor modify their behavior. There were two types of persistence behavior within our sample. The first type, relatively uncommon, related to those literally homeless informants who persisted in isolated locations. Scott, whom we previously mentioned in regard to the deteriorating climate in Pomona, has been homeless off and on (a total of six months) over the past three years, after being expelled from his sister's house when he became openly gay. He was staying in a trainyard with a number of other homeless people in Pomona, but also stayed at a church and a Cold Wet Weather shelter while it was open. Despite police harassment and a general lack of services in this suburban setting, Scott had no plans to leave Pomona anytime soon and had thus far managed to avoid being displaced.

The second type of persistence occurs when informants seek refuge in local institutional spaces, thereby holding their ground but typically at the cost of being "stuck" in marginal spaces where most shelters in Los Angeles County are located (57\% according to Table 3). At the time of the interview, Ann, a 38-year-old Black female, was living in a shelter in a poor neighborhood south of Downtown L.A. that is close to where she grew up and where her relatives live. She preferred this to the streets, and appreciated the 
proximity to family and friends. Stephen, a 40-year-old White male with long brown hair dressed in blue jeans and a white t-shirt, was experiencing his second episode of homelessness, which has lasted about six months. At the time of the interview in 2003, he lived in a shelter in a marginal space in Santa Monica, a city that he praised as being particularly sympathetic to homeless people: "It's really amazing in this particular city, I guess Santa Monica probably has more tolerance than anywhere else. It seems like the poor in general, they'd rather get rid of them."

For some, however, the feeling of being trapped outweighs the benefits of a servicerich (yet marginal) environment. Manny (a 38-year-old African American man) captured the feeling of entrapment while staying at a hotel on Skid Row:

I have been in here too long trapped inside and not aggressively trying to rectify this, you follow me? I won't say that I'm duckin' and dodging. I'm doing a lot of soul searching right now ... and I do a lot of that during the course of the day because I know that once I get back and I start living life on life's terms, it has to be a whole [lot] different, a totally different situation a whole [lot] different. I cannot, I don't want to stay down here and I think I told you I talked to people they've been here $17,15,5$ years, 8 years. I don't want to be that.

Voice

Perhaps not surprising given the tendency in U.S. society to "blame the victim," there was a distinct lack of involvement in, as well as knowledge of, collective voice responses among the 25 homeless informants interviewed. This may also be connected to Wacquant's (2007) concept that resistance is unlikely among a group whose membershipin this case inhabiting destructive ghettoes, and in our case, homelessness - is to be avoided, as well as resistance being unlikely if the group has (unwillingly) internalized the shame and humiliation imposed on them by mainstream society (Bourdieu and Wacquant, 1992). When asked directly, only four individuals had actively engaged in collective acts of resistance and protest. For instance, Darren in Long Beach had joined the Long Beach CAN (Community Action Network) that organizes protests against, and meetings with, city officials regarding harassment and service provision. Winston pointed to an institutionally based initiative by PATH (People Assisting The Homeless), an emergency shelter between Hollywood and Downtown LA: "PATH ... they've been trying to get the police to be a little more understanding in dealing with homeless people, not doing sweeps, you know, get better toilet facilities for homeless people." Karla, a 37-year-old White woman, participates in protests in her locality. In her words, "It's not a crime to be poor. It is pretty damned sad if you take away the poor's right to talk, which is asking for help, because that's our freedom we're talking about. It's our basic need at times."

Conversely, three-fifths of those in the sample knew nothing about collective voice resistance. Manny again captured this general apathy:

I've never heard of people doing any type of protest. That's something that they don't do. If you tell them to move, they move. You kick 'em, they off and they gone. As far as standing up [for] what they believe in, when in all honesty they don't have any rights. They don't really fit in anywhere. You are already considered an outcast, 
your living conditions, what society has labeled you as or considers you as, so what kind of protest can you do? You are out living on the streets! Anything that they give you, you ought to be grateful for, you will be grateful.

Manny was not the only informant to feel that collective protest was rare, if not entirely unknown. Ted, a 51-year-old African American staying at a shelter in Koreatown, gave a similar opinion:

No, I haven't heard of any, any homeless person lobbying for their rights or ... I guess most of them just want to live. I know for a fact that if you're on the streets on a daily basis, like I said, it takes all of your energy just to eat and to stay alive.

Guillaume, a 54-year-old African American living in Venice Beach (prime area), simply said that although he was aware of collective resistance and protest, he was not interested and did not have the time. These experiences and statements confirm that overt, collective, and spectacular voice is quite rare, implying that the punitive framework's perspective can only downplay homeless resistance. We will return to this issue of overt versus covert resistance in greater detail in the next section.

\section{Resistance by Place-Type}

Despite our small sample and relatively limited coverage, some of the suggested differences among place-types in Table 1 were borne out, whereas certainly behaviors were almost entirely absent across all place-types (namely voice). Conversely, there was a cross-cutting presence of adaptation and exit. This speaks to the sense that conditions have worsened for homeless people, that there is increased and systematic pressure on the visibly homeless in particular, forcing many to adopt low-key, furtive, or exit strategies to stay in place. This also speaks to the intertwined power-resistance relationship, in which power over the homeless has interacted with their everyday survival patterns.

Within prime space $(n=5)$, only exit and adaptation were present. This is not surprising, given that prime spaces did require a low profile, such that there was absolutely no voice at all, just persistence, adaptation, and exit. Persistence tended to involve stealth rather than shelters, given the lack of institutional resources. Within transitional spaces ( $n$ $=7$ ), there was a range of persistence, adaptation, and occasionally exit behavior. The last was definitely related to the increased pressures on transitional spaces, especially as many municipalities sought to regenerate their moribund downtown areas. Marginal spaces $(n=13)$ were the only ones to feature voice (although still very low-key), as well as "persistence by institution," in which the presence of shelters allowed homeless people to remain in situ, exhibiting a lesser degree of adaptation. Of the 13 informants in marginal spaces, 11 were living in shelters, compared to 2 of 7 in transitional spaces and 1 of 5 in prime spaces. Although it is difficult to say with certainty why marginal spaces were so different from prime and transitional, we can suggest that there is a clear structuring of voice and persistence related to the distribution of social service organizations. Through well-organized NIMBY campaigns, wealthy (prime) communities are able to control the distribution of social services and thereby the resistance behaviors of homeless people, not to mention the channeling of housing options for the very poor to the cheapest (and 
most disadvantaged) parts of the county. Not only can prime spaces keep facilities away, they can also effectively distance themselves from homeless voice.

The results of resistance by place-type raised some additional issues. First, we acknowledge that some informants moved within and across place-types. From what we heard, the more mobile homeless informants attempted to adapt their behavior-including resistance behavior - to their surroundings. This brings up a key challenge in relating resistance behavior to place-type - that the latter's boundaries can be fuzzy, being ambiguously drawn by homeless people themselves. And second, our analysis of place-types beyond the typical inner-city spaces so often used in studies of homeless resistance confirms that such resistance is muted in more suburban, transitional, and exclusive areas.

\section{DISCUSSION AND CONCLUSIONS}

Our reconceptualization of resistance, both spatially and in terms of behavior, should be a marked improvement over the romanticizing-versus-ignoring everyday resistance dichotomy that clouds current understandings. Moving beyond this dichotomy allows us to detect resistance in its many (entangled) forms and settings, but without necessarily seeing everything that homeless people do as resistance (i.e., transgression). Relating microspatial resistance behaviors to the larger socioeconomic spaces of Los Angeles County, as well as combining fine-grained qualitative interviews with quantitative demographic analysis, represent a methodological and geographical innovation to understanding the homeless resistance-place relationship. Moreover, this study is implicitly exploratory, so that we were most interested in the feasibility (and potential replicability) of the mixed-method approach.

Exploratory as they are, our results have gone some distance toward recognizing the extent to which homeless individuals (or collectives) are actually practicing resistance on the ground, and within a context of escalating anti-homeless measures. It would seem from our preliminary analysis that there is little overt resistance among homeless people, even in marginal space, and that overarching constraints are leading to moderate resistance behaviors (i.e., persistence and adaptation) across all place-types. Resistance is occurring, but not in the dramatic, spontaneous fashion acknowledged by the punitive framework; it is more everyday and mundane, perhaps the victim of the internalized symbolic violence to which homeless people are commonly subjected (Bourdieu and Wacquant, 1992).

We can, however, read these results in a different way, whereby the very existence, place-boundedness, and survival of homeless people can be equated to a kind of "resistance by persistence." Persistence and adaptation are forms of resistance wherein homeless people stand their ground in the face of increasing constraints and efforts to remove them. Of course, we wish to avoid romanticizing this sort of immobility, and to avoid seeing every transgression as resistance. We are thus compelled to return to Cresswell's (1996) original distinction between resistance and transgression. The immobility implied in the persistence and adaptation of certain homeless individuals is certainly transgressive within a context of rampant displacement, eviction, and sweeps of homeless people throughout Los Angeles County. This transgression comes at a cost of being servicedependent, living under strict rules, or modifying behavior/appearance. However, immobility can go beyond these and be considered resistance in the cases in which truly 
autonomous spaces are created by or for homeless people that exist independently, and represent an explicit refusal, of mainstream services (Hopper, 2006). In this way, resistance emerged in the form of occupying encampments (e.g., Scott in Pomona) that eluded the gaze of officials. Building on the 1990s resistance literature, we can certainly orient our model of resistance toward the likelihood of this kind of transgression and resistance, rather than wait for the more overt (and exceedingly rare) collective voice recognized by the punitive framework. The very existence and geography of shelters forms the basis for, and virtually assures, persistence within service-rich areas. Thus homeless people can survive, they are not just victims, and they do not simply disappear under the weight of punitive, anti-homeless laws (DeVerteuil, 2006; DeVerteuil et al., 2009).

A number of issues for future consideration can be identified. First, our understanding of resistance is based entirely on the informants' experiences, but homeless resistance is already known to be shaped by the geography of shelters and other human services that cater to homeless people. Shelter operators are themselves under pressure to discipline and conceal homeless people (DeVerteuil, 2004), but they could theoretically contribute to homeless resistance, especially adaptation and persistence. This would require interviewing operators about their perceptions regarding the hardening context of homelessness to ultimately situate the shelter system in relation to resistance. Second, it may be useful to use the U.S. Census Transportation Planning Package to better grasp daily movements between place of residence and place of work, which would facilitate classifying parts of the county with respect to daytime workplace populations. And third and finally, given the feasibility of the methods used here, we could employ a larger sample of homeless people. This would allow us to further hone our analysis by focusing on one particular cluster, and thereby better explore the micro-macro relationship in terms of which environments are most likely to engender and perhaps sustain homeless resistance.

\section{REFERENCES}

Abu-Lughod, L., 1990, The romance of resistance: Tracing transformations of power through Bedouin women. American Ethnologist, Vol. 23, 41-56.

Bourdieu, P. and Wacquant, L., 1992, An Invitation to Reflexive Sociology. Cambridge, UK: Polity Press.

Bratt, R., Stone, M., and Hartman, C., 2006, A Right to Housing: Foundation for a New Social Agenda. Philadelphia, PA: Temple University Press.

Brown, M. F., 1996, On resisting resistance. American Anthropologist, Vol. 98, 729-735.

Collins, D. and Blomley, N., 2003, Private needs and public space: Politics, poverty, and anti-panhandling by-laws in Canadian cities. In Law Commission of Canada, New Perspectives on the Public-Private Divide. Vancouver, Canada: University of British Columbia Press, 40-67.

Cresswell, T., 1996, In Place, Out of Place. Minneapolis, MN: University of Minnesota Press.

Culhane, D. and Fried, M., 1988, Paths in homelessness: A view from the street. In J. Friedrichs, editor, Affordable Housing and the Homeless. Berlin, Germany: DeGruyter Press, 175-187. 
DeVerteuil, G., 2003, Homeless mobility, institutional settings, and the new poverty management. Environment and Planning A, Vol. 35, 361-379.

DeVerteuil, G., 2004, Systematic inquiry into barriers to researcher access: Evidence from a homeless shelter. The Professional Geographer, Vol. 56, 372-380.

DeVerteuil, G., 2006, The local state and homeless shelters: Beyond revanchism? Cities, Vol. 23, 109-120.

DeVerteuil, G., May, J., and Von Mahs, J., 2009, Complexity not collapse: Recasting the geographies of homelessness in a "punitive" age. Progress in Human Geography, Vol. 33, No. 5.

DeVerteuil, G. and Wolch, J., 2002, Cast adrift in the post-911 city. Geoforum, Vol. 33, 273-274.

Erlandson, D., Harris, E., Skipper, B., and Allen, S., 1993, Doing Naturalistic Inquiry. Beverly Hills, CA: Sage Publications.

Hartman, C., Keating, D., and LeGates, R., 1982, Displacement: How to Fight It. Washington, DC: National Housing Law Project.

Hirschman, A., 1970, Exit, Voice, and Loyalty: Responses to Decline in Firms, Organizations, and States. Cambridge, MA: Harvard University Press.

Hopper, K., 2006, Redistribution and its discontents: On the prospects of committee work in public mental health and like settings. Human Organization, Vol. 65, 218-226.

Hopper, K., Susser, E., and Conover, S., 1985, Economies of the makeshift: Deindustrialization and homelessness in New York City. Urban Anthropology, Vol. 14, 183-236.

Johnsen, S., May, J., and Cloke, P., 2008, Imag(in)ing "homeless places": Using autophotography to (re)examine the geographies of homelessness. Area, Vol. 40, 194-207.

Laurenson, P. and Collins, D., 2007, Beyond punitive regulation? New Zealand local governments' responses to homelessness. Antipode, Vol. 39, 649-667.

Levia, D. and Page, D., 2000, The use of cluster analysis in distinguishing farmland prone to residential development: A case study of Sterling, Massachusetts. Environmental Management, Vol. 25, 541-548.

Lofland, J., 2006, Analyzing Social Settings: A Guide to Qualitative Observation and Analysis. Belmont, CA: Wadsworth/Thomson.

May, J., 2000a, Housing histories and homeless careers: A biographical approach. Housing Studies, Vol. 15, 613-638.

May, J., 2000b, Of nomads and vagrants: Single homelessness and narratives of home as place. Environment and Planning D: Society and Space, Vol. 18, 737-759.

Merrifield, A., 2000, The dialectics of dystopia: Disorder and zero tolerance in the city. International Journal of Urban and Regional Research, Vol. 24, 473-489.

Molina, G., 2000, Informal non-kin networks among homeless Latino and African American men. American Behavioral Scientist, Vol. 43, 663-685.

Mitchell, D.,1997, The annihilation of space by law: The roots and implications of antihomeless laws in the United States. Antipode, Vol. 29, 303-335.

National Coalition for the Homeless, 2007, Feeding Intolerance: Prohibitions on Sharing Food with People Experiencing Homelessness. Washington, DC: National Coalition for the Homeless.

Rogerson, P., 2001, Statistical Methods for Geography. Thousand Oaks, CA: Sage Publications. 
Ruddick, S., 1996, Young and Homeless in Hollywood: Mapping Social Identities. London, UK and New York, NY: Routledge.

Sassen, S., 2001, The Global City (second revised edition). Princeton, NJ: Princeton University Press.

Scott, A., 2001, Introduction. In A. Scott, editor, Global City-Regions: Trends, Theory, Policy. New York, NY: Oxford University Press, 1-8.

Sharp, J., Routledge, P., Philo, C., and Paddison, R., 2000, Entanglements of power: Geographies of domination/resistance. In J. Sharp et al., editors, Entanglements of Power: Geographies of Dominantion/Resistance. London, UK and New York, NY: Routledge, 1-42. [Author: Please provide the first 6 editors names and initials for Sharp et al. (followed by "et al." if there are more than 6).]

Shelter Partnership, 2000, Short-Term Housing Directory of Los Angeles County, April 2000. Los Angeles, CA: Shelter Partnership, Inc.

Smith, N.,1996, The New Urban Frontier: Gentrification and the Revanchist City. London, UK and New York, NY: Routledge.

Snow, D. and Mulcahy, M., 2001, Space, politics, and the survival strategies of the homeless. American Behavioral Scientist, Vol. 45, 149-169.

Takahashi, L., 1996, A decade of understanding homelessness in the USA: From characterization to representation. Progress in Human Geography, Vol. 20, 44-69.

U.S. Census, 2000, Census Tract files. Washington, DC: U.S. Census Bureau.

von Mahs, J., 2005, The socio-spatial exclusion of homeless people in Germany and the United States. American Behavioral Scientist, Vol. 48, 928-960.

Wacquant, L., 2007, Urban Outcasts: A Comparative Sociology of Advanced Marginality. Cambridge, UK: Polity Press.

Wagner, D., 1993, Checkerboard Square: Culture and Resistance in a Homeless Community. Boulder, CO: Westview Press.

Wolch, J., 2008, Intransigent LA. Geoforum, Vol. 39, 543-545.

Wolch, J. and Dear, M., 1993, Malign Neglect: Homelessness in an American City. San Francisco, CA: Jossey-Bass.

Wright, T., 1997, Out of Place: Homeless Mobilizations, Subcities, and Contested Landscapes. Albany, NY: State University of New York.

Wyly, E. and Hammel, D., 2005, Mapping Neoliberal American Urbanism. In R. Atkinson and G. Bridge, editors, Gentrification in a Global Context: The New Urban Colonialism. London, UK and New York, NY: Routledge, 18-38. 